\title{
Reducing Pesticide Drift by Considering Propeller Rotation Effects From Aerial Application Near Buffer Zones
}

\author{
Steven J. Thomson ${ }^{1}$, Alvin R. Womac ${ }^{2} \&$ Joseph E. Mulrooney ${ }^{3}$ \\ ${ }^{1}$ USDA Agricultural Research Service, Crop Production Systems Research Unit, Midsouth Area, USA \\ ${ }^{2}$ Biosystems Engineering and Environmental Science, Univ. of Tennessee, USA \\ ${ }^{3}$ USDA Forest Service, Wood Products Insect Research Unit, Southern Research Station, USA (retired) \\ Correspondence: Steven J. Thomson, USDA, ARS, CPSRU, P.O. Box 350, Stoneville, MS 38776, USA. Tel: \\ 1-662-686-5240. E-mail: steve.thomson@ars.usda.gov
}

Received: February 1, 2013 Accepted: April 18, 2013 Online Published: April 23, 2013

doi:10.5539/sar.v2n3p41 URL: http://dx.doi.org/10.5539/sar.v2n3p41

\begin{abstract}
Off-target drift of chemical from agricultural spraying can damage sensitive crops, destroy beneficial insects, and intrude on human and domestic animal habitats, threatening environmental quality. Reduction of drift from aerial application can be facilitated at the edge of a field by offsetting spray $1 / 2$ or 1 boom width from the field edge or by switching off one boom. For single boom application (and especially when spraying in a cross wind), there is some question whether off-target drift of sprayed crop protection agent is influenced by which boom is spraying and if direction of propeller rotation has any effect. An experiment was conducted to determine the effect of propeller wash rotation on aerial spray drift from turbine-powered aircraft. Spray samplers were placed at three sample lines to collect drift fallout and air-entrained particles 104, 134, 195, and 317 meters downwind, perpendicular to the flight path. An aqueous mixture of malathion was applied from the aircraft through fifty hollow cone nozzles. Five total replications were conducted over two days. Each replication had four treatment combinations of actively spraying boom and airplane direction. Results showed that neither active boom nor boom location (upwind or downwind) was statistically significant for either sampling method at the 0.05 level. Blocking the study to account for weather differences increased statistical precision. Thus when analysis was limited to the second day of testing, propeller wash direction was significant at the 0.10 level for the fallout sheets $(\mathrm{P}=0.0773)$, and at the 0.05 level for high volume $(\mathrm{Hi}-\mathrm{Vol})$ air samplers $(\mathrm{P}=0.0200)$. Higher concentrations occurred when propeller wash spiraled downwind. Based on results of this study, recommendations for pilots spraying with a single boom near a boundary is to spray so that propeller wash rotation occurs upwind.
\end{abstract}

Keywords: aerial application, drift control, agricultural aircraft, pesticide application, buffer zone, propeller wash

\section{Introduction}

Off-target drift of chemical applied to crop fields can cause damage to sensitive crops downwind from the intended target, destroying beneficial insects and infringing on human and domestic animal habitats (Ware, 1983). Experimental determination of off-target drift from aerial application of crop protection agents continues to be a challenge. Meteorological effects, atomization variables, and aircraft spray systems all interact to make this issue a complex problem. Increasing pressure to reduce off-target spray drift has resulted in government agency requirements for buffer zones of significant width between application and potentially sensitive areas (Amos, 2010).

Simulation models can allow evaluation of various scenarios for their effects on spray drift. One such model has been used to estimate drift as a function of aircraft parameters and relies on droplet size distributions (Teske et al., 2002). Bird et al. (2002) and Teske et al. (2002) have published results from limited aerial application trials to assess the validity of the AgDrift model for aerial application. Huang et al. (2012) detailed a method called "Design of Experiments" (DOE) that used MATLAB and the AGDISP (Agricultural DISPersion) model (Teske et al., 2003) to study the major contributory factors for spray drift. The method was designed to provide some guidance to applicators and maximize application efficiency by placing constraints on wind speed, spray release 
height, and droplet size. One key component of this methodology was calculation of spray offset distance for drift reduction to compensate for wind speed. Hoffmann et al. (2010) conducted experiments to evaluate drift reduction nozzles using a wind tunnel and laser diffraction instrument. Resulting droplet spectra were input into the AGDISP model, and results included swath displacement (or an offset away from the edge of the field) in the calculations. The authors found only marginal improvements in drift reduction percentages by offsetting the swath, but strong benefit was indicated for increasing deposition of material within the field.

When planning a spray drift study, it is important to consider proper sampling methods that are also amenable to convenient post-application analysis. Felsot (2005) presented a detailed summary of drift assessment and mitigation methods that indicated appropriate application of passive and active samplers. Passive samplers such as mylar sheets and alpha cellulose collectors are commonly used for sampling spray fallout, and active samplers use vacuum pumps to pull air laden with pesticide through sampling media that can include filters or solid adsorbent media (Millet, 2008). Lewis (1976) indicated usefulness of powered "active" air samplers placed near the breathing zone of a monitored individual for determining the inhalable fraction of pesticide. Morshed et al. (2011) used both passive and active samplers that included personal air sampling, for a study on application of glyphosate from a mist blower. The authors found that passive sampling performed better in residue uptake performance than their vacuum pump active sampling method for glyphosate.

For spray drift studies, either inert tracers (de Cerqueira et al., 2012) or active ingredient (AI) can be applied and analyzed. If they are feasible to use, AI have advantages to assure integrity of droplet size and spray characteristics. Malathion is an organophosphate insecticide that was instrumental in the Boll Weevil eradication program on cotton, as well Medfly control and mosquito control (Newhart, 2006). Significant inhalation of malathion is low at customary temperatures because of its low vapor pressure (ATSDR, 2012), but volatilization was reported in a study conducted in agricultural conditions of Italy (Ferrari et al., 2003). However, the rate of pesticide vaporization and drop evaporation of a wide range of pesticide sprays under field conditions may not be adequately predicted, thereby increasing the usefulness of a field sampling approach (Amin et al., 1999). Bui et al. (1998) compared spray sampling methods for collection of malathion and concluded that samplers using high volume (Hi-Vol) air pumps can collect similar amounts of airborne spray of malathion. It was also concluded that samplers that do not utilize Hi-Vol pumps collected less drift of malathion.

As has been indicated, buffers zones of significant width are required to protect sensitive areas (Amos, 2010). There has thus been interest by aerial applicators in the use of Best Management Practices (BMP) for drift control, which includes aerial application upwind from the edge of the field using a swath offset or displacement. For application from a single boom, the relative effects from either upwind or downwind wings and the direction of propeller wash on spray drift would be important to determine and understand. There are implications for both near-field and far-field drift, and knowing the relative impacts for drift would influence the width of required spray buffer zone (Felsot, 2004). Propeller wash turbulence carries droplets from nozzles to the right of the fuselage and deposits them beneath or to the left of the fuselage. This results from the clockwise propeller air helix spiraling into the fuselage (Univ. of Nebraska, 2004). Huddleston et al. (1994) performed an experiment where left and right booms of an aircraft were alternately switched, and drift of malathion and chlorpyrifos were detected using string samplers placed 33 and $91 \mathrm{~m}$ downwind. Results suggested that the right boom contributed more to drift than the left boom by the Boom*Position (upwind/downwind) interaction $33 \mathrm{~m}$ downwind $(\mathrm{p}=$ $0.0251)$ There was also significant interaction at the $10 \%$ level $(\mathrm{p}=0.0968)$ at the $91 \mathrm{~m}$ sampler distance. Wind speeds ranged from 1.3 to $3.1 \mathrm{~m} / \mathrm{s}$ throughout the test, but it was not clear whether wind speed or direction were accounted for in the statistical design. Preliminary analysis conducted by Thomson et al. (2004) found that propeller wash direction and propeller wash interaction with sampler distance were all significant at $p=0.10$ from fallout sheets used as spray sampling media. There was no corresponding significance using Hi-Vol samplers. The study only considered the weather variables wind speed and direction and did not adjust downwind sampler distances for changing wind direction.

The study presented herein expands on that performed by Thomson et al. (2004). It attempts to quantify spray drift differences between left and right booms and determine the influence of propeller wash direction and downwind sampled concentration of malathion. Downwind sampler distance was adjusted for changing wind direction and the experiment was designed to account for discernible weather differences by 'blocking' the experiment on time of day or, in this case, the different days during which partial replications were made. The latter was meant to determine whether potential improvements in statistical precision would be enough to influence results. Data from both Hi-Vol and fallout samplers were analyzed. Weather variables air temperature, relative humidity, solar radiation, wind speed, and wind direction were measured and considered in the analysis. 


\section{Materials and Methods}

\subsection{Field Setup and Deployment of Spray Samplers}

The spray tests were conducted over an early cotton crop, and layout of samplers is illustrated in Figure 1 . The cotton was planted in $1 \mathrm{~m}$ rows and was generally 0.2 to $0.3 \mathrm{~m}$ tall across the 60 ha rectangular test area. The spray area with cotton rows was oriented so that the prevailing wind was blowing at nearly $90^{\circ}$ to the direction of aircraft travel. Nine horizontal 25.4 by $25.4 \mathrm{~cm}$ alpha cellulose spray sampling sheets were placed $3 \mathrm{~m}$ apart on same-sized boards in the swath to collect in-swath deposit and at three sample lines to collect drift fallout 104, 134, 195, and 317 meters downwind, perpendicular to the flight path. At each sample line, the samplers were placed $30 \mathrm{~m}$ apart and mounted in a horizontal plane $0.5 \mathrm{~m}$ above the ground surface on collection boards attached with new spring clips. For sampler deployment, clean rubber gloves were used, and pre-labeled, plastic zip-lock bags were placed at the side of the field in alignment with the three replicate collectors at each distance from the spray area and nine in the spray swath. Hi-Vol vacuum motor air samplers with $10.2 \mathrm{~cm}$ diameter $(81$ $\mathrm{cm}^{2}$ surface area) TFA2133 glass fiber filters collected airborne drift and were oriented vertically. They were placed at the same intervals downwind as the alpha cellulose samplers. These Hi-Vol air samplers were utilized to measure the air-entrained off-target drift that was likely to be moving across a downwind crop head-high. Droplet drift at this height provides an indication of how much material might be inhaled downwind from the spray zone. The Hi-Vol samplers were mounted at a height of $1.8 \mathrm{~m}$ above ground level and were set to a flow rate of $0.68 \mathrm{~m}^{3}$ of air per minute through the filter.
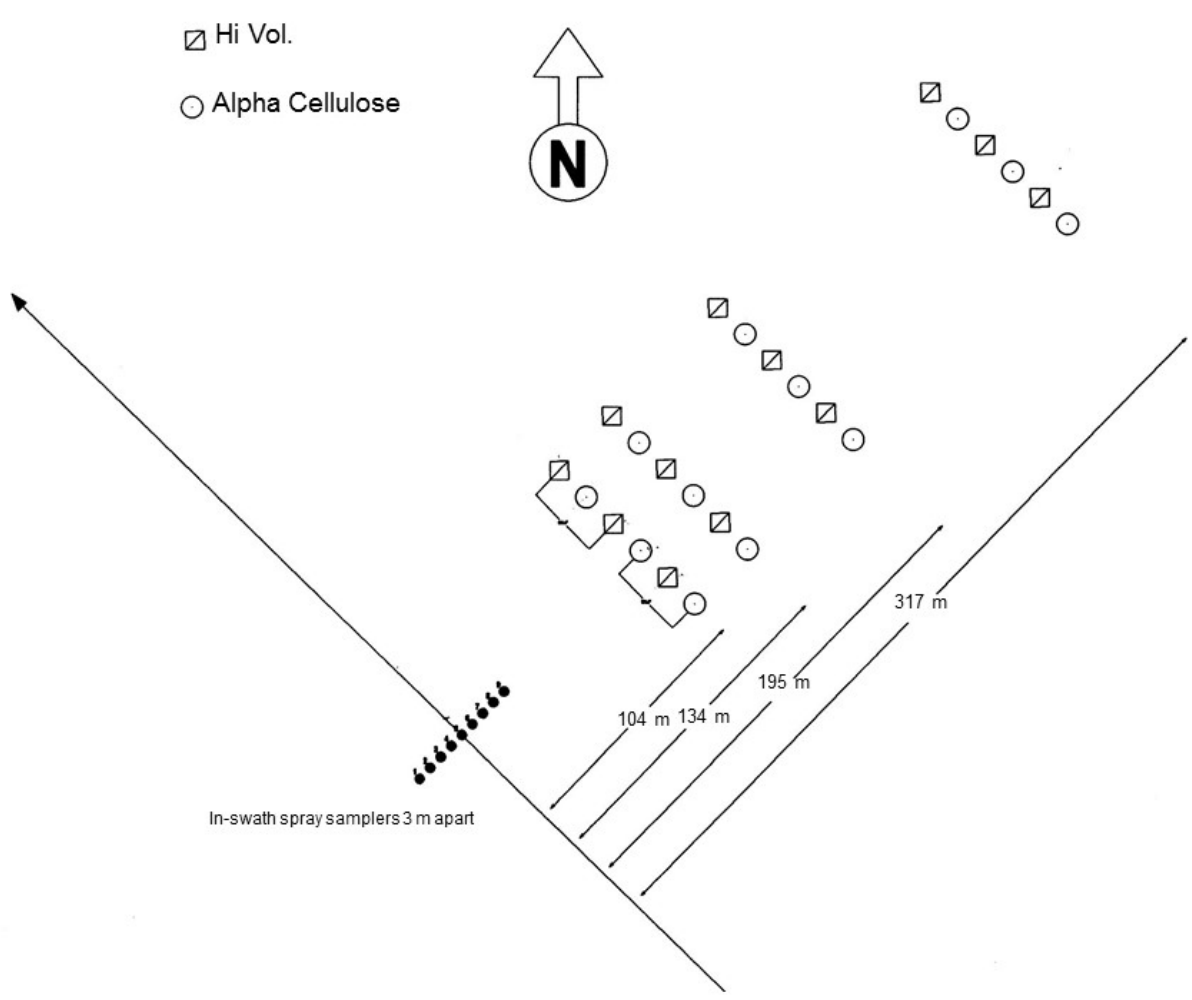

Figure 1. Field sampler layout. Flight path was perpendicular to in-swath sampler line as shown, in either direction as specified by the experiment

\subsection{Application System}

An aqueous mixture of malathion at a spray rate of $19 \mathrm{~L} / \mathrm{ha}$ was applied from an Air Tractor 402B aircraft through fifty D6-46 hollow cone tips (Teejet Technologies, Wheaton, IL, USA) at a release height of $3.7 \mathrm{~m}$ and directed straight down to induce drift. Nominal boom operating pressure was $137 \mathrm{kPa}\left(20 \mathrm{lb} / \mathrm{in}^{2}\right)$ corresponding to an approximate per-nozzle flow rate of $2.91 / \mathrm{min}$. Swath width was $23 \mathrm{~m}$ and aircraft speed was $56 \mathrm{~m} / \mathrm{s}$. Volume Median Diameter (VMD) droplet size was modeled as $212 \mu \mathrm{m}$ under these conditions and at the low operating pressure (APMRU, 2012). VMD or D [v, 0.5] is where half of the volume of spray contains droplets 
larger than the VMD. Approximately 41\% of the spray volume showed droplet diameter of $200 \mu \mathrm{m}$ or less by the D6-46 nozzle model under these operating conditions, which is a favorable setup for inducing drift. Each study replication had four treatment combinations of boom switch (left "L" or right "R" booms actually spraying) and orientation of the spraying boom on the aircraft (upwind "U" or downwind "D") as illustrated in Figure 2. For each treatment, four passes were made applying $0.11 \mathrm{~kg}$ chemical $/$ ha on each pass. All tests were conducted under wind conditions that would be considered conducive to off-target drift. Weather conditions were measured on-site at 1.8, 3, and $9 \mathrm{~m}$ tower heights using a Campbell Scientific 21X logger. Table 1 indicates meteorological variables measured during the study.

Table 1. Meteorological conditions during study. Reps 1 and 2 were conducted on day one and Reps 3-5 were conducted on day two. Treatment numbers correspond to experimental treatment ordering illustrated in Figure 2

\begin{tabular}{|c|c|c|c|c|c|c|c|c|c|}
\hline REP & Treatment & $\begin{array}{l}\text { Mean } \\
\text { Air } \\
\text { Temp } \\
\left({ }^{\circ} \mathrm{C}\right)\end{array}$ & $\begin{array}{c}\text { Mean } \\
\text { RH } \\
(\%)\end{array}$ & $\begin{array}{c}\text { Mean } \\
\text { Solar } \\
\text { Irradiance } \\
\left(\mathrm{kW} / \mathrm{m}^{2}\right)\end{array}$ & $\begin{array}{c}\text { Mean } \\
\text { Wind } \\
\text { Velocity } \\
(\mathrm{m} / \mathrm{s})\end{array}$ & $\begin{array}{c}\text { Std. } \\
\text { Dev.of } \\
\text { Wind } \\
\text { Velocity } \\
(\mathrm{m} / \mathrm{s})\end{array}$ & $\begin{array}{c}* \text { Mean } \\
\text { Wind } \\
\text { Direction } \\
\text { (degrees) }\end{array}$ & $\begin{array}{l}\text { Std. Dev } \\
\text { of Wind } \\
\text { Direction } \\
\text { (degrees) }\end{array}$ & $\begin{array}{c}\text { Stability } \\
\text { Ratio } \\
\left({ }^{\circ} \mathrm{Cs}^{2} / \mathrm{m}^{2}\right)\end{array}$ \\
\hline 1 & 1 & 27.86 & 47.81 & 0.95 & 4.09 & 2.21 & 1.63 & 9.46 & -0.22 \\
\hline 1 & 2 & 28.35 & 46.32 & 0.89 & 5.69 & 0.97 & -3.10 & 11.01 & -0.22 \\
\hline 1 & 3 & 29.03 & 44.24 & 0.84 & 5.58 & 0.68 & -0.83 & 6.30 & -0.22 \\
\hline 1 & 4 & 28.48 & 45.31 & 0.37 & 5.19 & 0.55 & 4.90 & 12.46 & -0.17 \\
\hline 2 & 1 & 28.84 & 44.05 & 0.62 & 4.78 & 0.51 & 2.41 & 11.17 & -0.22 \\
\hline 2 & 2 & 28.97 & 42.63 & 0.53 & 5.02 & 0.80 & -7.97 & 4.00 & -0.22 \\
\hline 2 & 3 & 29.04 & 42.39 & 0.43 & 4.80 & 0.51 & 2.78 & 13.15 & -0.21 \\
\hline 2 & 4 & 29.02 & 42.77 & 0.35 & 4.37 & 0.66 & -3.35 & 4.06 & -0.22 \\
\hline 3 & 1 & 24.79 & 74.56 & 0.68 & 5.47 & 0.86 & -9.71 & 9.41 & -0.19 \\
\hline 3 & 2 & 25.28 & 74.24 & 0.63 & 3.28 & 0.50 & -28.60 & 18.67 & -0.49 \\
\hline 3 & 3 & 26.64 & 64.10 & 0.96 & 3.98 & 0.60 & -6.46 & 14.33 & -0.40 \\
\hline 3 & 4 & 28.23 & 55.00 & 0.94 & 3.61 & 1.18 & 8.34 & 14.78 & -0.57 \\
\hline 4 & 1 & 28.65 & 56.63 & 0.91 & 3.93 & 0.64 & -17.48 & 12.48 & -0.38 \\
\hline 4 & 2 & 29.04 & 54.52 & 0.96 & 4.29 & 0.87 & -14.71 & 13.81 & -0.35 \\
\hline 4 & 3 & 29.61 & 54.35 & 0.93 & 3.90 & 0.75 & -29.36 & 18.99 & -0.44 \\
\hline 4 & 4 & 29.51 & 55.59 & 0.79 & 3.31 & 1.15 & -26.84 & 13.37 & -0.65 \\
\hline 5 & 1 & 29.82 & 50.88 & 0.86 & 3.80 & 0.91 & -21.78 & 13.68 & -0.51 \\
\hline 5 & 2 & 29.62 & 50.95 & 0.42 & 4.07 & 0.55 & 10.37 & 11.81 & -0.33 \\
\hline 5 & 3 & 29.53 & 52.13 & 0.32 & 3.97 & 0.73 & -42.07 & 18.70 & -0.36 \\
\hline 5 & 4 & 29.38 & 52.17 & 0.28 & 3.94 & 0.55 & -55.30 & 5.02 & -0.28 \\
\hline
\end{tabular}

* Mean wind direction is relative to the sampler line. 


\section{Wind direction}

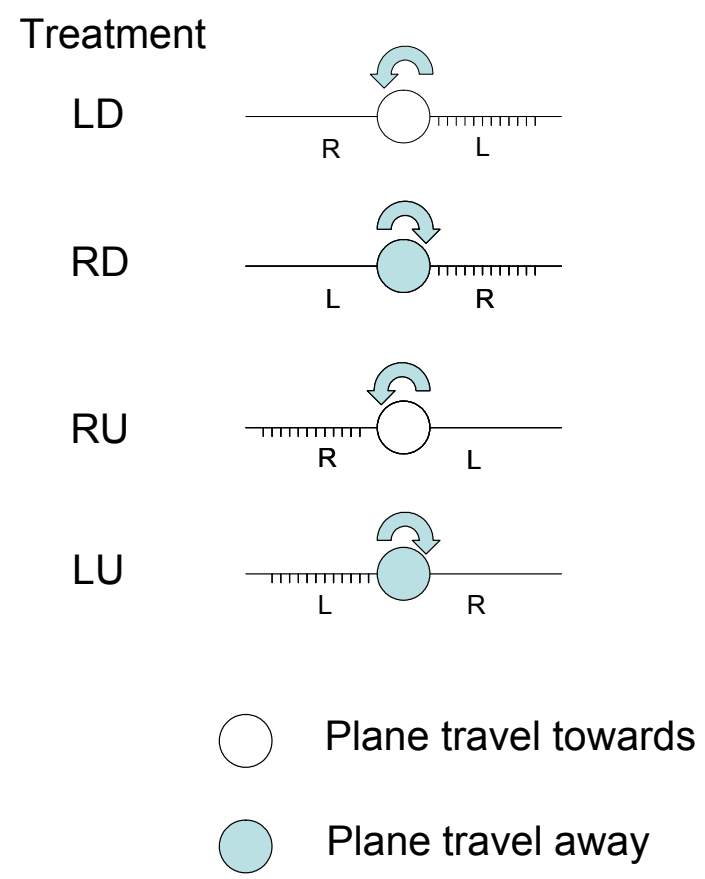

Figure 2. Experimental treatments. Arrows designate propeller direction; Left "L" or right "R" booms; boom location upwind "U" or downwind " $\mathrm{D}$ "

\subsection{Sample Collection}

The same people who deployed fresh collectors also collected the samples. Field personnel used new rubber gloves to pick up the collector bags. Alpha-cellulose samples were detached from the backing board by removing the spring clips and discarding them. Each alpha-cellulose sample was immediately put into the proper pre-labeled large collection bag. This procedure was repeated for each of the nine alpha-cellulose samples in the swath and three alpha-cellulose samples at each downwind distance. The Hi-Vol collectors were each removed from their mounts and placed in small pre-labeled bags. The samples were returned to the edge of the field and immediately placed into ice chests where they were protected from light.

\subsection{Sample Analysis}

Sample analysis procedures followed those described by Gaultney et al. (1996) and are summarized herein. Pesticide was extracted from the horizontal alpha-cellulose collectors by first cutting the alpha-cellulose into five strips measuring $5.08 \mathrm{~cm}$ long. The five strips were cut in half and placed in a $946 \mathrm{~mL}$ wide-mouth glass jar with $300 \mathrm{~mL}$ of ethanol. The jars were placed on their sides in a laboratory platform reciprocating shaker and were shaken for $30 \mathrm{~min}$. The alpha-cellulose was then squeezed and removed from the jar, and the effluent left in the jar was placed in a rotary evaporator and evaporated down to $10 \mathrm{~mL}$. The sample was then ready for gas chromatograph (GC) analysis of malathion tracer. The GC used for the sample analysis was a Hewlett-Packard (HP) gas chromatograph Model 5890 equipped with a HP Model 7673 autosampler with an autoinjector, and a HP Model 19256A flame photometric detector in the phosphorous mode. The operation of the GC was through the HP Chemstation software. Analysis of the Hi-Vol air sampler filters followed a similar procedure as the alpha-cellulose. The only difference between the two procedures was that the air sampler filters were cut into thirds and placed in a $946 \mathrm{~mL}$ wide-mouth glass jar with $100 \mathrm{~mL}$ of ethanol instead of the $300 \mathrm{~mL}$ used with the larger collectors.

\subsection{Statistical Analysis}

Residue data were analyzed using PROC Mixed in SAS 9.3 (SAS, 2009), and correlation of variables with concentration of malathion were determined at each sampling distance. For the study presented herein, 
downwind distances were adjusted for each run to account for wind direction. Since weather differences occur between days and during different parts of a day, the experiment was analyzed both over the entire five replications encompassing two days and three replications conducted on the second day of testing only. For statistical analysis, a log transform was applied to the dependent variable 'concentration' and downwind sampling distance. Using the log transform gave the best model fit as verified with SAS runs of PROC GLM. Covariance parameter estimates and non-significant variables showing little effect were progressively removed from the model as their presence influenced results.

\section{Results and Discussion}

\subsection{Variable Correlations}

Table 2 illustrates correlations between weather variables and concentration of malathion at four discrete sampling distances. Relative humidity and solar radiation showed negative correlation, while temperature and wind velocity showed positive correlation across sampling methods. Wind velocity showed a greater effect as downwind distance increased. An inverse relationship of downwind concentration with relative humidity was expected, since water in the spray droplets is more likely to evaporate at low relative humidity, decreasing droplet size and increasing the chances for drift (Ware, 1983). Solar radiation was a very strong influence, and this was also confirmed over many analysis runs. Higher solar radiation probably increased dispersion of spray droplets, decreasing sampled concentration. Evaporation facilitated by sunlight should also reduce droplet size.

Table 2. Pearson correlations (R) between selected weather variables and spray collections of malathion for fallout sheets and Hi-Vol samplers at four downwind distances

\begin{tabular}{lclllllll}
\hline & \multicolumn{3}{c}{ Fallout Sheets } & \multicolumn{5}{c}{ Hi-Vol Samplers } \\
\hline Variable & $104 \mathrm{~m}$ & $134 \mathrm{~m}$ & $195 \mathrm{~m}$ & $317 \mathrm{~m}$ & $104 \mathrm{~m}$ & $134 \mathrm{~m}$ & $195 \mathrm{~m}$ & $317 \mathrm{~m}$ \\
Temperature & 0.0283 & 0.2410 & 0.3828 & 0.2956 & 0.5530 & 0.5139 & 0.4541 & 0.4595 \\
Relative Humidity & -0.2966 & -0.4390 & -0.5715 & -0.6611 & -0.5162 & -0.4668 & -0.4704 & -0.6707 \\
Solar Radiation & -0.4486 & -0.3341 & -0.7117 & -0.7252 & -0.6236 & -0.6830 & -0.8004 & -0.8019 \\
Wind Velocity & 0.2492 & 0.1405 & 0.3311 & 0.5313 & 0.1414 & 0.1005 & 0.1718 & 0.4012 \\
\hline
\end{tabular}

\subsection{Statistical Model Results}

Over the five replications for fallout samplers, none of the effects BOOM (actively spraying boom), UD (boom location, upwind or downwind), or $\mathrm{BOOM}^{*} \mathrm{UD}$ interaction were statistically significant at the 0.05 level $(\mathrm{p}=$ $0.7600, p=0.3183, p=0.4572$ respectively). Similar results were seen for the Hi-Vol samplers, although influence was a bit stronger $(\mathrm{p}=0.4613, \mathrm{p}=0.1530, \mathrm{p}=0.2838$, respectively). There was a significant REP (replication) effect for the fallout sheets $(\mathrm{p}=0.0409)$. Solar radiation was significant at the 0.01 level for both fallout sheets and Hi-Vol samplers $(p=0.0043 ; p=0.0021$, respectively). It should be noted that BOOM*UD interaction indicates propeller wash direction (PW). This was verified by interchanging both $\mathrm{BOOM} * \mathrm{UD}$ and PW into the model and as expected, using either term gave identical results.

Confining analysis to the second day of testing (replications 3, 4, and 5 only) indicated different statistical results over those obtained using the complete set of replications. Here, BOOM*UD interaction (or PW) was significant at the 0.10 level for the fallout sheets $(\mathrm{P}=0.0773)$ and at the 0.05 level for Hi-Vol samplers $(\mathrm{P}=0.0200)$. For all cases (and as expected), the log of downwind sampler distance (LDIST) was significant at the 0.01 level. LDIST*Wind Direction was significant at the 0.01 level for the second-day analysis for both fallout sheets and Hi-Vol samplers. This indicates that the magnitude of wind direction effect varied significantly according to distance from the spray swath.

\subsection{Graphical Representation of Trends}

Trends verifying differences due to propeller wash rotation effects for Hi-Vol samplers are illustrated graphically in Figures $3 \mathrm{a}$ and $3 \mathrm{~b}$. Effective sampler distances were adjusted for prevailing wind direction by the cosine of the angle between downwind sampler line and wind direction. The data were pooled across left and right booms in upwind or downwind positions, and best-fit curves were calculated using CurveExpert 1.5 (Hyams, 2012). It is clear from both plots that higher concentrations occurred when propeller wash spiraled downwind, and this occurred when the airplane was heading Southeast (Figure 1) with either boom spraying (treatments LD or RU, 
Figure 2). LDIST*PW interaction for Hi-Vol samplers was significant $(p=0.0317$ ) as the PW effect could be seen to vary highly with downwind distance for the case limited to three replications (Figure $3 b$ ). In both Figures $3 \mathrm{a}$ and $3 \mathrm{~b}$, sample variability for $\mathrm{PW}=$ downwind was higher than the $\mathrm{PW}=$ upwind case as evidenced by the relative $r^{2}$ values. Boom position (UD) and LDIST*UD interaction were significant at the 0.05 level $(p=0.0254$ and $\mathrm{p}=0.0295$, respectively) for the Hi-Vol samplers. Figure 4 shows that downwind sample concentrations of malathion appeared slightly lower for upwind oriented booms, as might be expected. Differences appeared to diminish somewhat with distance.

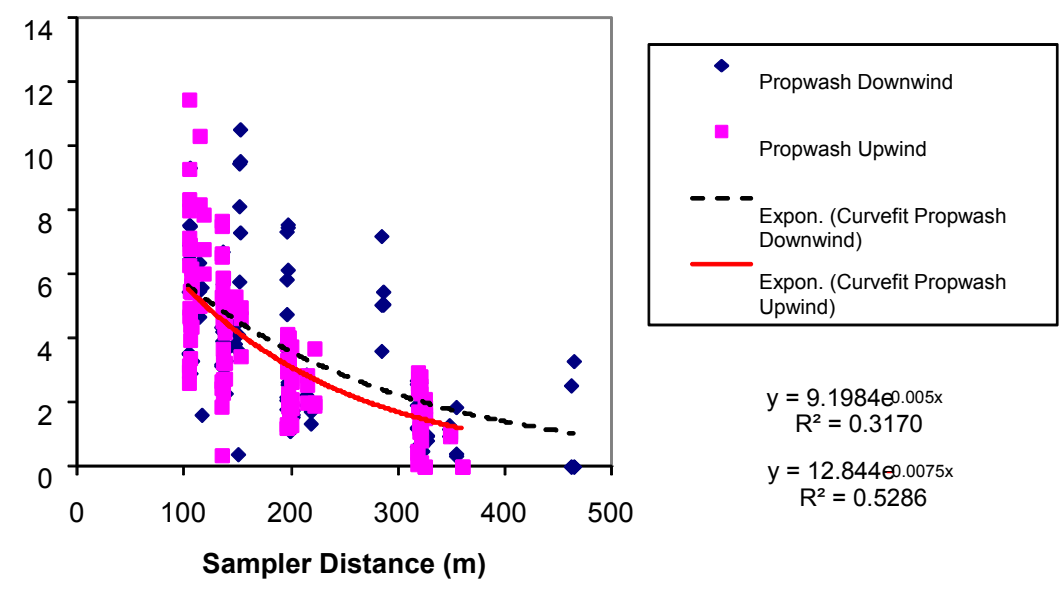

Figure 3a. Propeller wash effect illustrated by sampler distance vs. concentration of malathion across all replications for Hi-Vol samplers

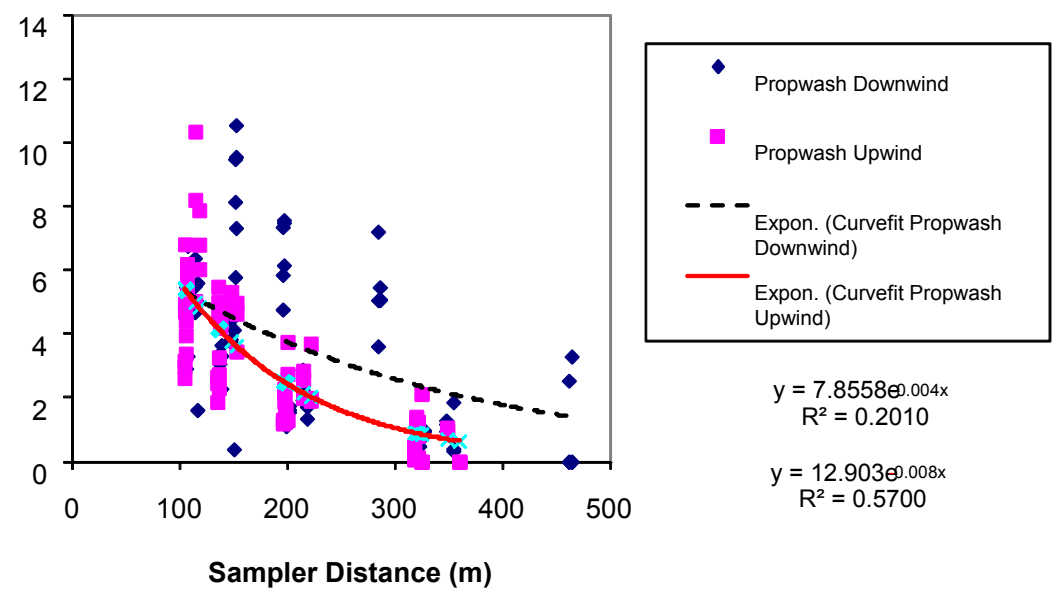

Figure 3b. Propeller wash effect illustrated by sampler distance vs. lab concentration of malathion across replications 3,4 , and 5 on second day of testing for Hi-Vol samplers

Trends verifying differences due to propeller wash rotation effects for fallout samplers are illustrated graphically in Figures $5 \mathrm{a}$ and $5 \mathrm{~b}$. Trends are quite similar to those from Hi-Vol samplers, and it is clear here also that increased statistical precision was obtained by limiting the test to three replications on the second day of testing. LDIST*PW interaction for fallout samplers was significant at the 0.10 level $(p=0.0841)$ for the case limited to three replications (Figure 5b). This is a weaker effect than the Hi-Vol trend suggests (Figure 3b) as the curves are more parallel. However, the curvilinear nature of the trend assures an interaction effect. 

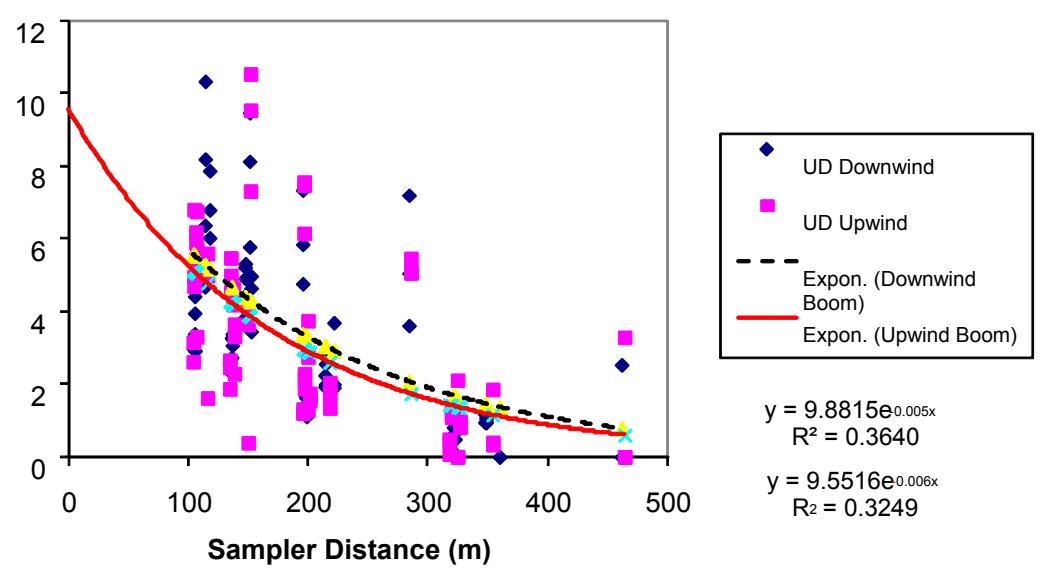

Figure 4. Boom position effect illustrated by sampler distance vs. lab concentrations of malathion across replications 3, 4, and 5 on second day of testing for Hi-Vol samplers
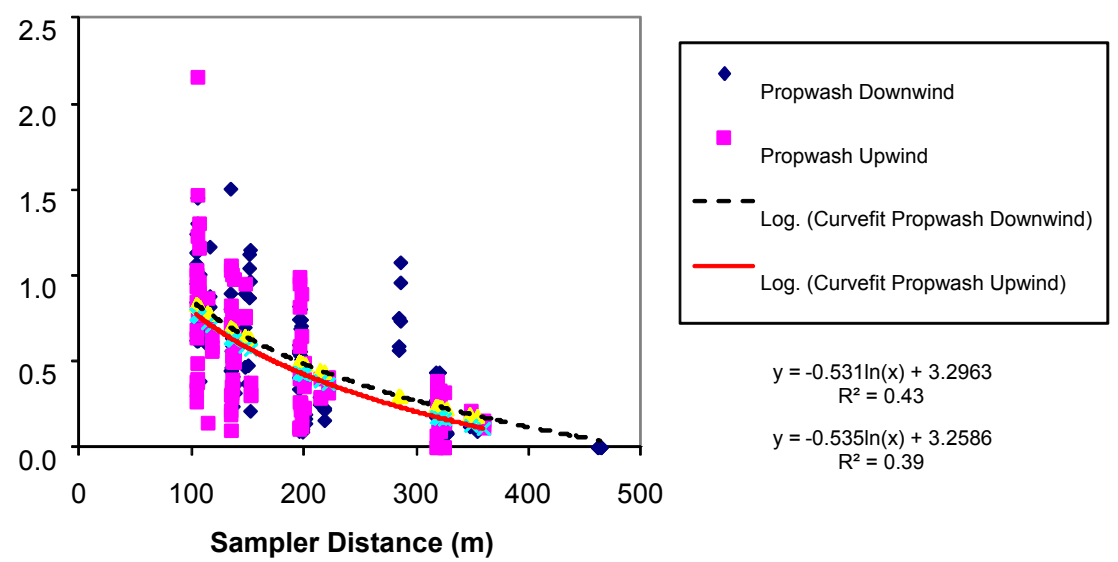

Figure 5a. Propeller wash effect illustrated by sampler distance vs. lab concentration of malathion across all replications for fallout samplers
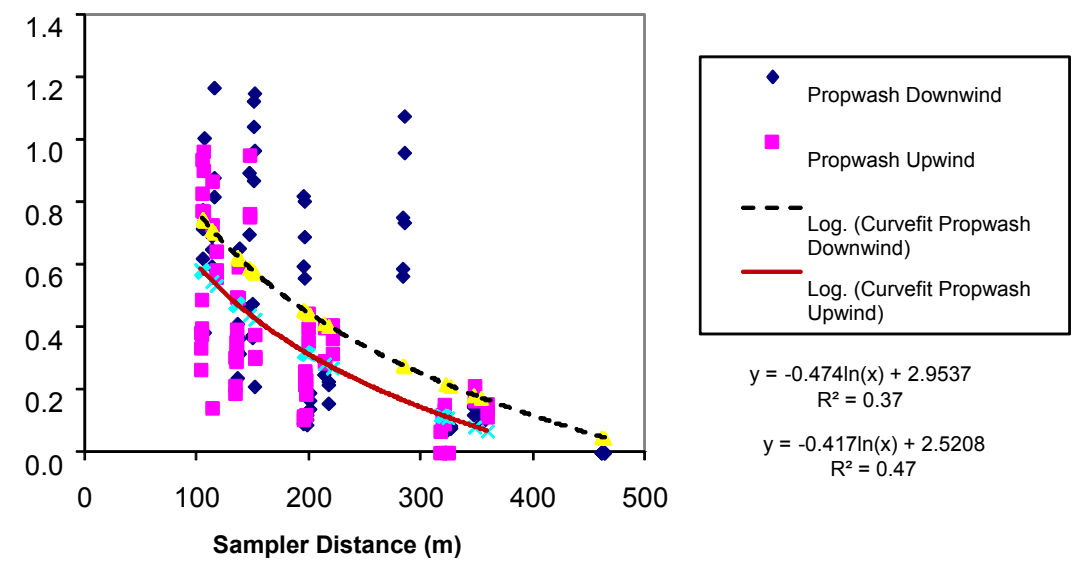

$$
y=-0.474 \ln (x)+2.9537
$$$$
\begin{aligned}
& y=-0.417 \ln (x)+2.5208 \\
& R^{2}=0.47
\end{aligned}
$$

Sampler Distance (m)

Figure 5b. Propeller wash effect illustrated by sampler distance vs. lab concentration of malathion across replications 3,4 , and 5 on second day of testing for fallout samplers 


\subsection{Further Considerations}

This study was greatly assisted by the fact that wind speed was not highly variable. However, it was still difficult to ascertain exact wind conditions at a sampling point. During the course of analysis, different methods were used to ascertain wind speed and direction in an effort to best represent wind conditions over the four passes per run. The analysis illustrated herein used an average of four wind speeds at the beginning of each pass (over four passes) per run. Estimates were also made of how long it might take for a spray cloud to arrive at the most distant sampler for one method tried. This proved to be problematic, however, since wind data were obtained only once per minute over the four passes. Although difficult to apply in practice, a reference spray applied simultaneously with every treatment could be used to remove environmental effects (such as that specified in ASABE, 2004). This might be especially useful when more highly variable wind conditions are encountered. Hi-Vol samplers were set at a fixed volumetric flow rate of $0.68 \mathrm{~m}^{3} / \mathrm{min}$, corresponding to a wind speed of about $1.4 \mathrm{~m} / \mathrm{s}$. This was much less than the wind speeds observed for our study, so readings would tend to be less than actual concentration of malathion due to anisokinetic conditions (Hinds, 1982). Although wind was not highly variable, any change in wind speed would cause sample concentration to be biased up or down, requiring compensation by measuring wind at each sampler or use of an isokinetic sampler such as one described by Thomson and Smith (2000). Filters used in the Hi-Vol samplers probably did not collect all malathion going through them. Additional polyurethane foam (PUF) filters placed behind the primary filter have been shown to collect additional spray (Bui et al., 1998; Amin et al., 1999). Varying wind direction would also influence sampler collection efficiency, but both wind speed and direction were unusually consistent for this study, providing excellent experimental conditions. Differences in spray release height can affect spray drift and although height was not monitored, a highly experienced and steady agricultural pilot was used to aid uniformity in release height.

Results indicated herein agreed well with the results previously reported by Huddleston et al. (1994), although data interpretation may be slightly different. Our study equated Boom and Boom Position (UD) interaction with propeller wash direction, not an implication that differences in sampled concentration were caused by which boom was spraying. In fact, both Huddleston's study and our study confirmed that boom effect (by itself) showed no statistically significant effect on concentration. For our study, the boom effect was greatest when analysis was limited to three replications on the second day of testing $(p=0.1319)$ for fallout sheets, although not statistically significant at the 0.05 level. Similar results are also notable because Huddleston's study could be cast as more of a near-drift study, while our samplers were placed at greater distances downwind. Statistical precision seemed to increase with analysis of second-day data (three replications) as compared with data pooled across all five replications, as demonstrated graphically in Figures 3 and 5. This difference was particularly pronounced for the fallout samplers. Observations are consistent with a study of spray deposition (Thomson et al., 2007), where the experiment was blocked on time of day significantly increasing statistical precision and highlighting the importance of proper accounting of weather variables.

\section{Conclusions}

Based on results, the following conclusions can be made regarding treatment effects on downwind sampled concentration of malathion:

a. Treatments applied with direction of propeller wash rotation that rolled in the upwind direction tended to reduce drift.

b. Propeller wash effects on sampled concentration were more pronounced with increasing sampler distance for both sampling methods.

c. Variability of downwind sample collections was lower when propeller wash direction was upwind.

d. Statistical precision increased by separating analysis according to replications associated with day of the experiment.

\section{Disclaimer}

Mention of a trade name, proprietary product, or specific equipment does not constitute a guarantee or warranty by the U.S. Department of Agriculture or the University of Tennessee and does not imply approval of the product to the exclusion of others that may be available.

\section{References}

Amin, M. K., Womac, A. R., Bui, Q. D., Mueller, T. C., \& Mulrooney, J. E. (1999). Air sampling of aerosol and gaseous pesticides. Transactions of the ASAE, 42(3), 593-600. 
Amos, G. (2010). Buffer zones, no spray zones. Presented at the $10^{\text {th }}$ annual conference of The Pesticide Stewardship Alliance (TPSA), Feb 23, 2010, Savannah, GA. Retrieved from http://tpsalliance.org/10_PDFs/agenda/6A-Amos-buggerZones-2010.pdf

APMRU. (2012). Aerial spray nozzle models. Retrieved from http://apmru.usda.gov/aerial/AERIAL\%20SPRAY\%20NOZZLE\%20MODELS\%20(Technical\%20Version) .html

ASABE. (2004). Procedure for measuring drift deposits from ground, orchard, and aerial sprayers. ASAE Standard S561.1 APR2004 (R2009). St. Joseph, MI USA: ASABE.

ATSDR. (2012). Material safety data sheet - Malathion. Retrieved from http://www2.udec.cl/matpel/hazardous_materials/malathion.pdf

Bird, S. L., Perry, S. G., Ray, S. L., \& Teske, M. E. (2002). Evaluation of the AgDISP aerial spray algorithms in the AgDRIFT model. Environmental Toxicology and Chemistry, 21(3), 672-681. http://dx.doi.org/10.1002/etc.5620210328

Bui, Q. D., Womac, A. R., Howard, K. D., Mulrooney, J. E., \& Amin, M. K. (1998). Evaluation of samplers for spray drift. Transactions of the ASAE, 41(1), 37-41.

de Cerqueira, D. T. R., Raetano, C. G., do Amaral Dal Pogetto, M. H. F., Prado, E. P., Christovam, R. S., Serra, M. E., \& Almeida Costa, S. I. (2012). Agricultural spray deposit quantification methods. Applied Engineering in Agriculture, 28(6), 825-831.

Felsot, A. S. (2004). Establishing buffers: Protocols and toxicological benchmarks. In Proc. International Conference on Pesticide Application for Drift Management. October 27- 29, Waikoloa, HI., 199-203.

Felsot, A. S. (2005). Evaluation and mitigation of spray drift. Retrieved from http://feql.wsu.edu/esrp531/Fall05/FelsotCostaRicaDrift.pdf

Ferrari, F., Trevisan, M., \& Capri, M. (2003). Predicting and measuring environmental concentrations of pesticides in air after soil application. Journal of Environmental Quality, 32, 1623-1633. http://dx.doi.org/10.2134/jeq2003.1623

Gaultney, L. D., Howard, K. D., \& Mulrooney, J. E. (1996). Off-target drift with air-assisted agricultural sprayers. In H.M. Collins, G. R. Goss, M. Hopkinson (Eds.), Pesticide Formulations and Application Systems, ASTM STP 1312 (Vol 16). West Conshohocken, Pennsylvania, USA: American Society for Testing and Materials. http://dx.doi.org/10.1520/STP11343S

Hinds, W. C. (1982). Aerosol technology: properties, behavior, and measurement of airborne particles. Isokinetic Sampling (pp. 187-194). New York, NY: John Wiley and Sons.

Hoffmann, W. C., Fritz, B. K., Thornburg, J. W., Bagley, W. E., Birchfield, N. B., \& Ellenberger, J. (2010). Spray drift reduction evaluations of spray nozzles using a standardized testing protocol. Journal of ASTM International, 7(8), Paper ID JAI102820.

Huang, Y., Zhan, W., Fritz, B. K., \& Thomson, S. J. (2012). Optimal selection of controllable variables to minimize downwind drift from aerially applied sprays. Transactions of the ASABE, 28(3), 307-314.

Huddleston, E. W., Ross, J. B., Ledson, T. M., Sanderson, R., Kilgore, G. M., \& Clason, D. L. (1994). Right wing-left wing difference in drift. Technical paper AA94-004, National Agricultural Aviation Association (NAAA) Washington D.C.: NAAA.

Hyams, D. (2012). CurveExpert professional 1.5 comprehensive curve fitting software for Windows. (C Daniel Hyams 2012. Retrieved from http://www.curveexpert.net/

Lewis, R. G. (1976). Sampling and analysis of airborne pesticides. In R. E. Lee Jr. (Ed.), Air Pollution from Pesticides and Agricultural Process (pp. 51-94), Cleveland, Ohio: CRC Press, Inc.

Millet, M. (2008). Sampling and analysis of pesticides in the atmosphere. In J. L. Tadeo (Ed.), Analysis of pesticides in food and environmental samples (pp. 257-283), Boca Raton, FL, USA: CRC Press, Inc. http://dx.doi.org/10.1201/9781420007756

Morshed, M. M., Omar, D., Mohamad, R. B., \& Wahed, S. B. A. (2011). Determination of glyphosate through passive and active sampling methods in a treated field atmosphere. African Journal of Agricultural Research, 6(17), 4010-4018.

Newhart, K. (2006). Environmental fate of malathion. California Environmental Protection Agency, Department 
of Pesticide Regulation, Environmental Monitoring Branch. Retrieved from http://www.cdpr.ca.gov/docs/emon/pubs/fatememo/efate_malathion.pdf

SAS. (2009). The Statistical Analysis (SAS) System, Version 9.3. Cary, NC: SAS Institute.

Teske, M. E., Bird, S. L., Esterly, D. M., Curbishley, T. B., Ray, S. L., \& Perry, S. G. (2002). AgDRIFT®: a model for estimating near-field spray drift from aerial applications. Environmental Toxicology and Chemistry, 21(3), 659-671. http://dx.doi.org/10.1002/etc.5620210327

Teske, M. E., Thistle, H. W., \& Ice, G. G. (2003). Technical advances in modeling aerially applied sprays. Transactions of the ASABE, 46(4), 985-996.

Thomson, S. J., \& Smith, L. A. (2000). Evaluation of a control system for isokinetic hi-volume sampling of airborne spray. Applied Engineering in Agriculture, 16(3), 309-314.

Thomson, S. J., Womac, A. R., Mulrooney, J. E., \& Deck, S. (2004). Evaluation of upwind/downwind boom switching and propeller direction on drift of aerially applied spray. In Proc. International Conference on Pesticide Application for Drift Management, October 27-29, Waikoloa, HI, 340-347.

Thomson, S. J., Young, L. D., Bright Jr, J. R., Foster, P. N., \& Poythress, D. D. (2007). Effects of spray release height and nozzle/atomizer configuration on penetration of spray in a soybean canopy - preliminary results. Technical paper AA07-008, National Agricultural Aviation Association (NAAA) Washington D.C.: NAAA.

Univ. of Nebraska. (2004). Aerial Pest Control, Chapter 3, Calibration. Pesticide Education Resources. University of Nebraska, Lincoln, NE. Retrieved from http://pested.unl.edu/catmans/aerial.skp/aerch3.htm

Ware, G. W. (1983). Reducing pesticide application drift losses. Pesticide Application Drift Training Manual Task Group and the University of Arizona Cooperative Extension Service. Retrieved from http://pesticides.hawaii.edu/studypackets/driftlos.html 